\title{
Universiteit
}

Leiden

The Netherlands

\section{Making Disability Work? The Effects of Financial Incentives on Partially Disabled Workers}

Koning, P.W.C.; Sonsbeek, J.M. van

\section{Citation}

Koning, P. W. C., \& Sonsbeek, J. M. van. (2017). Making Disability Work? The Effects of Financial Incentives on Partially Disabled Workers. Labour Economics, 47, 202-215. doi:10.1016/j.labeco.2017.05.008

Version: $\quad$ Publisher's Version

License: $\quad$ Leiden University Non-exclusive license

Downloaded from: https://hdl.handle.net/1887/54704

Note: To cite this publication please use the final published version (if applicable). 


\title{
Making disability work? The effects of financial incentives on partially disabled workers
}

\author{
Pierre Koning ${ }^{\mathrm{a}, \mathrm{c}, \mathrm{d}, \mathrm{e}, *}$, Jan-Maarten van Sonsbeek ${ }^{\mathrm{a}, \mathrm{b}}$ \\ ${ }^{a}$ VU University Amsterdam, Department of Economics, De Boelelaan 1105, P.O. Box 80510, NL 1081 HV Amsterdam, The Netherlands \\ b Ministry of Social Affairs and Employment, The Hague, The Netherlands \\ ${ }^{\mathrm{c}}$ Leiden University, The Netherlands \\ d Tinbergen Institute, Amsterdam, The Netherlands \\ e IZA, Bonn, Germany
}

\section{A R T I C L E I N F O}

\section{JEL codes:}

I38

I13

Keywords:

Disability insurance

Financial incentives

\begin{abstract}
A B S T R A C T
This study uses longitudinal administrative data from the Netherlands to explore the responsiveness of disabled workers to financial incentives. We focus on workers with partial Disability Insurance (DI) benefits that have substantial residual work capacities. When the first phase of benefit entitlement to DI has expired, these workers experience a dramatic drop in income if they do not employ their residual income capacity. Entitlement periods to the first phase of DI benefits vary across individuals. This enables us to estimate the impact effect of this change in work incentives on the incidence of work, on wage earnings and on full work resumption. Based on the estimation results, the implied labor force non-participation elasticity rate equals 0.12 . Response estimates are highest among young DI recipients, who typically have shorter entitlement periods to the more generous first phase of DI benefits. The incentive change has a limited impact on wage earnings of partially disabled workers and no significant impact on full work resumption.
\end{abstract}

\section{Introduction}

In recent years, increasing attention has been devoted to the design of work incentives for disabled workers (OECD, 2010). Several studies indicate the presence of residual work capacities among Disability Insurance (DI) recipients that are left unused as a result of high implicit tax rates (see e.g. Bound, 1999, and Maestas et al., 2014). At the same time, Autor and Duggan (2006) and Bütler et al. (2015) argue that vouchers like the Ticket-to-Work program in for Social Security Disability Insurance (SSDI) in the US and lump-sum payments in Switzerland - as a complement to DI benefits - do not compensate for perverse insurance incentives. Thus, policymakers are in search for better-targeted and more effective incentive schemes for DI recipients.

This study explores how dramatic increases in financial incentives during the benefit spell affect the employment, wage earnings and DI exits of partially disabled workers. Our analysis uses registered data from disabled workers in the Netherlands between 2006 and 2013 who are deemed to have substantial residual earning capacities; this group constitutes about $16 \%$ of the total inflow into DI. ${ }^{1}$ In the first phase of DI benefit entitlement - the so-called 'wage-related period ' - an individual receives supplementary Unemployment Insurance (UI) benefits if his or her residual earning capacity is left unused. This ensures total benefit payments of at least $70 \%$ of the individual's predisability wage earnings. When wage-related DI benefits are exhausted and the 'continuation period' starts, DI benefit levels remain constant if an individual employs at least $50 \%$ of his or her residual earning capacity. If the $50 \%$ requirement is not met, however, DI benefit levels are linked to the level of minimum wages instead of pre-disability wages. This 'kink' in the level of DI benefits, combined with the simultaneous termination of income from supplementary UI benefits, induces a strong incentive to work in the continuation period, particularly for workers with high pre-disability earnings.

Our analysis exploits the fact that the length of the wage-related period of DI recipients depends on the work history of a worker. This induces substantial variation in the duration of benefit entitlement from three months at minimum to 60 months at maximum in the time

\footnotetext{
* Corresponding author at: VU University Amsterdam, Department of Economics, De Boelelaan 1105, P.O. Box 80510, NL 1081 HV Amsterdam, The Netherlands.

E-mail addresses: p.w.c.koning@vu.nl (P. Koning), j.m.van.sonsbeek@vu.nl (J.-M. van Sonsbeek).

${ }^{1}$ The Dutch DI system, which has been plagued by moral hazard problems for several decades, provides an interesting setting for the current analysis. See Koning and Lindeboom

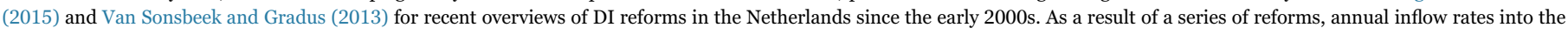
DI scheme decreased from $1.5 \%$ of the working population in 2000 to about $0.5 \%$ from 2006 onwards.
} 
period under consideration. ${ }^{2}$ Assuming that the exact timing of the incentive change at the moment of benefit exhaustion is unrelated to changes in the ability to work, we disentangle incentive effects from duration dependency effects that affect the prevalence of work and wage earnings. We carefully model the evolution of the duration dependency effects in individual panel regressions. We use flexible specifications for baseline patterns for outcome variables across separate age groups, as the age of individuals is correlated to the length of the wage-related period and may also affect the recovery patterns of DI recipients over the benefit spell.

We add to a strand of literature that addresses the effects of financial work incentives on workers who are enrolled in DI schemes. For recent studies in this field, see Kostol and Mogstad (2014), Campolieti and Riddell (2012), and Weathers and Hemmeter (2011). ${ }^{3}$ Specifically, our paper makes three important contributions that are linked to the unique design of partial DI benefits in the Netherlands. First, changes in work incentives do not stem from wage subsidies or vouchers that supplement DI benefits, but rather from benefit reductions for disabled workers without sufficient employment earnings. If workers dislike losses in income more than they like income gains, one would thus expect higher work responses to the incentive change (Tversky and Kahneman, 1991). Second, the incentives we study are targeted at workers that are deemed to have residual earning capacities. We thus are the first to study the effect of financial incentives that are embedded in partial DI schemes - as opposed to the more general DI schemes that are used in most OECD countries (OECD, 2010). Finally, the set-up of the partial DI system induces strong differences in the observed incentive changes when the wagerelated period ends, which allows us to study whether incentive responses are proportional to the size of the incentive change.

Our main finding is that the change in work incentives at the end of the wage-related period leads to a 2.5 percentage-point increase in work incidence. This effect corresponds to a labor force non-participation elasticity estimate of 0.12 . This estimate is close to estimates of Kostol and Mogstad (2014), who find elasticity estimates between 0.1 and 0.3 for the work incidence of disabled workers in Norway. We thus find no evidence that response effects to the change in incentives were higher for the sample of partial DI recipients in the Netherlands - at least, not when comparing them to the full population of disabled workers in Norway. One possible explanation for this is that participation rates were already high in the group of DI recipients at the start of their DI spell, causing the remaining group of disabled workers without employment to be less responsive to the incentive change.

We also find strong evidence that labor supply effects at the extensive margin are proportional to the size of the incentive change. That is, higher drops in the replacement rate for partially disabled workers at the moment of benefit exhaustion yield higher labor responses. The estimated effects on wage earnings suggest that most of the behavioral effects are channeled by increases in labor supply at the extensive margin - and not by increases in hours worked. Moreover, the limited and insignificant effects that we find for the incentive change on full work resumption indicate that partially disabled workers preferred supplementing their partial DI benefits by wage earnings to being fully employed while receiving wage earnings only. This is in line with analyses of Campolieti and Riddell (2012) for Canada, and Weathers and Hemmeter (2011) for the US, who conclude

\footnotetext{
${ }^{2}$ The wage-related period of DI benefits is unrestricted for workers who are awarded full DI benefits. The length of the wage-related period is not related to the earning capacity (but benefits are related to the loss of the earning capacity, of course).

${ }^{3}$ When taking a broader perspective, incentive effects are also studied by comparing DI applicants who are awarded with benefits with those who are rejected (Bound, 1999; Maestas et al., 2013; Chen and van der Klaauw, 2008; Moore, 2015; Autor et al., 2014; French and Song, 2014). In addition, some studies exploit variation in DI benefits over time or between regions to examine effects on DI enrolment or DI return-to-work rates (Gruber, 2000; Autor and Duggan, 2003; Campolieti, 2004; Fevang et al., 2013).
}

that earnings disregards lead to employment effects but not to increases in exits from SSDI.

The remainder of this paper proceeds as follows. Section 2 explains the institutional background of the Dutch DI scheme for partially disabled workers, as well as the expected impact of the partial DI program on work, wage earnings and the likelihood of leaving the scheme. Sections 3 and 4 present the data and the empirical strategy and Section 5 discusses our estimation results. Finally, Section 6 concludes.

\section{Institutional background}

\subsection{Disability determination and the DI benefit programs ${ }^{4}$}

Since its inception in 1967, the Disability Insurance (DI) program in the Netherlands is a public scheme that is mandatory for all workers. DI benefits provide insurance for 70 percent of the loss of income due to disabilities of any kind, regardless of their cause. Workers apply for DI benefits after two years of sickness absence. DI claims are assessed and DI premiums are set by the Dutch public Employee Insurance Agency (UWV). UWV determines the presence of impairments, the remaining earning capacity and the resulting degree of disability as a percentage of a worker's pre-disability wage.

To assess an individual's degree of disability, an insurance doctor and a UWV-designated labor market expert select a set of at least nine regular jobs that meet the worker's physical and mental impairments and current level of education. These jobs are derived from a database called CBBS (the 'Client Administration and Assurance System'), which contains about 7000 jobs that are located at about 3500 firms (UWV, 2013). Each job is described by an educational level, work pattern, labor experience and 55 types of work strains that may or may not be relevant. The earning capacity of an individual is set equal to the median value of average wage rates of the nine selected jobs; the disability degree that follows from this is equal to the loss of earning capacity as a percentage of the pre-disability wage. Individual workers are subsequently assigned to six disability classes with the following degree intervals: $0-35 \%, 35 \%-45 \%$, 45\%-55\%, 55\%-65\%, 65\%-80\%, and $80 \%-100 \%$.

Workers with disability degrees that are lower than 35\% are not entitled to any DI benefits. As we will argue later on, this may cause a 'cash-cliff' in total income. That is, if a worker that initially was deemed to earn less than $65 \%$ of pre-disability earnings starts receiving a wage which is more than $65 \%$ of his or her pre-disability earnings, this will ultimately lead to the full loss of DI benefits.

Workers with disability degrees between $35 \%$ and $80 \%$ receive partial DI benefits. This group typically has mental and behavioral disorders, musculoskeletal impairments or circulatory system diseases (Koning and Lindeboom, 2015). For each of the four disability degree intervals between $35 \%$ and $80 \%$, the benefit level of these workers is based on its central value; this corresponds to $40 \%, 50 \%, 60 \%$ and $72.5 \%$ of pre-disability earnings, respectively. Using intervals of disability degrees in this way implies that wage earnings may exceed the earnings capacity regularly without adaptations in the registration of disability degrees. As long as the disability degree that follows from the wage earnings remains in the relevant interval for disability degrees, the initial earnings capacity that is registered will not be adapted and the benefit level thus remains unaffected.

Workers are classified as fully disabled if their degree of disability exceeds $80 \%$. If impairments for this group are regarded as temporary, workers receive full DI benefits - amounting to $70 \%$ of their pre-

\footnotetext{
${ }^{4}$ The Dutch DI benefit system contrasts to most other countries that do not allow for partial DI benefit schemes. Among OECD countries, the Czech Republic, Finland, Germany, Greece, Hungary, Korea, Norway, Portugal, Sweden and Switzerland are other countries which award DI benefits with levels that are related to the loss of earnings capacity (OECD 2010).
} 
disability earnings - but they are medically re-assessed after some years in the same way as for the initial assessment. Similar to workers with partial benefits, mental and musculoskeletal impairments and diseases of the circulatory system are most common among the DI recipient group designated 'fully and temporarily' disabled. Finally, workers that are assessed as 'fully and permanently' disabled receive full DI benefits that equal $75 \%$ of their pre-disability earnings. For this group, cancers and strokes are the most frequent diagnoses.

Since the introduction in 2006 of separate DI schemes for partially disabled workers, fully and temporarily disabled workers and fully and permanently disabled workers, DI inflow rates in the Netherlands have remained more or less constant over time (Koning and Lindeboom, 2015). Even though annual UI inflow rates more than doubled during the recession that started in 2009, the annual overall DI inflow rate remained stable at around $0.5 \%$ of the insured population. Also, the respective contributions of partially disabled workers (0.1\%), fully and temporarily disabled $(0.2 \%)$ and fully and permanently disabled workers $(0.2 \%)$ have been quite stable over the years (UWV, 2016). In contrast to empirical analyses that have been conducted for the Netherlands with data for the nineties, this indicates that DI benefits are no longer a viable alternative to long-term unemployment benefits (see e.g. Koning and van Vuuren, 2007).

\subsection{The level and duration of partial DI benefits}

Partially disabled workers in the Netherlands receive DI benefits in two successive phases: the wage-related period and the continuation period. Fig. 1 depicts how the entitlement length to the wage-related period increases with respect to the number of employment history years. Until 2008, increases in the length of entitlement followed a step function of the employment history, with 60 months of entitlement length at maximum. Since 2008, the length of the wage-related period is a linear function of employment years - with one additional year of employment resulting in one additional month of benefit entitlement and a maximum length of 38 months.

In the wage-related period of benefits, the partial DI scheme and the partial UI scheme function as complementary benefits. Accordingly, the length of entitlement connected to this period - where benefits are related to pre-disability earnings - is equal for both benefit types. In the continuation period of DI benefits, DI benefit levels remain linked to pre-disability earnings if an individual employs at least $50 \%$ of his or her residual earning capacity. If the $50 \%$ requirement is not met, however, DI benefit levels become linked to the level of the statutory minimum wage instead of pre-disability wages. For most workers, this induces a strong increase in the incentive to exploit the residual earning capacity,

With partial DI benefits that are complemented with partial UI benefits in the wage-related period of DI benefits, workers receive total

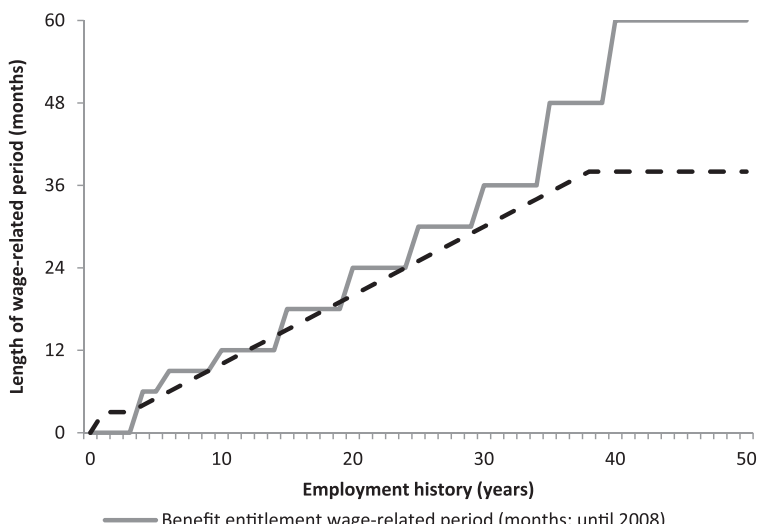

- - Benefit entitlement wage-related period (months; since 2008)

Fig. 1. Employment history (in years) and DI benefit entitlement (in months) to the wage-related period. benefits from DI and UI that are equal to $70 \%$ of the pre-disability wages at minimum, rendering the exact level of the disability degree irrelevant for workers without wage earnings. We define the worker's pre-disability wage as $W_{p}$ and $d$ as the disability degree of the relevant disability category of the worker, with $0.35 \leq d<0.80$ (this is the range of disability degrees with entitlement to partial benefits). The total benefit income in the wage-related period (WRP) while being unemployed $(u)$ then equals ${ }^{5}$ :

Income $_{u}^{W R P}=0.7 d W_{p}+0.7(1-d) W_{p}=0.7 W_{p}$

Now suppose we compare this income with the total income from benefits and wage earnings when the earnings capacity of the worker is used to it full extent. This yields the following income level for employed $(e)$ workers in the wage-related period:

Income $_{e}^{W R P}=0.7 d W_{p}+(1-d) W_{p}$

Based on Eqs. (1) and (2), we can derive the replacement rate of full usage of the earning capacity, also known as the 'average participation tax rate'. In the current context, we will refer to this variable as the 'conditional' replacement rate (CRR), as we condition on a given level of the disability degree category level of the worker $(d)$. In the wagerelated period, the conditional replacement rate of employing the earnings capacity makes clear that work incentives only vary with respect to the disability degree, $d$ :

$C R R^{W R P}=\frac{\text { Income }_{u}^{W R P}}{\text { Income }_{e}^{W R P}}=\frac{0.7 W_{p}}{0.7 d W_{p}+(1-d) W_{p}}=\frac{0.7}{1-0.3 d}$

When turning to the continuation phase of DI benefits, we have to bear in mind that workers without wage earnings do no longer receive DI benefits that are linked to pre-disability earnings but on the statutory minimum wage instead. Moreover, the receipt of complementary UI benefits has ended. Defining the statutory minimum wage as $W_{m}$, the total income from benefits for unemployed workers in the continuation period of DI, Income ${ }_{u}^{C P}$, will thus be equal to

Income $_{u}^{C P}=0.7 d W_{m}$

We stated earlier that the total income from benefits and wage earnings remains unaffected if the worker fully exploits his or her earning capacity. We thus can derive the conditional replacement rate in the continuation phase of DI benefits, $C R R^{C P}$ :

$$
\begin{aligned}
C R R^{C P} & =\frac{\text { Income }_{u}^{C P}}{\text { Income }_{e}^{C P}}=\frac{0.7 d W_{m}}{0.7 d W_{p}+(1-d) W_{p}} \\
& =\frac{0.7 d}{1-0.3 d}\left(\frac{W_{m}}{W_{p}}\right)=d\left(\frac{W_{m}}{W_{p}}\right) C R R^{W R P}
\end{aligned}
$$

This equation makes apparent that the conditional replacement rates decreases if one switches from the wage-related period to the continuation period of DI benefits. This change in the incentive to work increases in pre-disability earnings and decreases with respect to the disability degree of a worker.

\subsection{Effects of the incentive change for a representative worker}

To analyze the employment choices partially disabled workers are facing in greater detail, we now consider the specific case of a representative worker. We assume that the annual pre-disability earnings of this worker are equal to 34,500 Euros, which was the average wage income in the Netherlands in 2013. We also assume that the worker has a partner with substantial wage earnings, so there is no

\footnotetext{
${ }^{5}$ For expositional reasons, we abstract from the fact that there is a maximum premium wage by which pre-disability earnings can be capped. We also abstract from any supplementary benefits from social assistance (see Section 3.1 that describes the data set-up).
} 


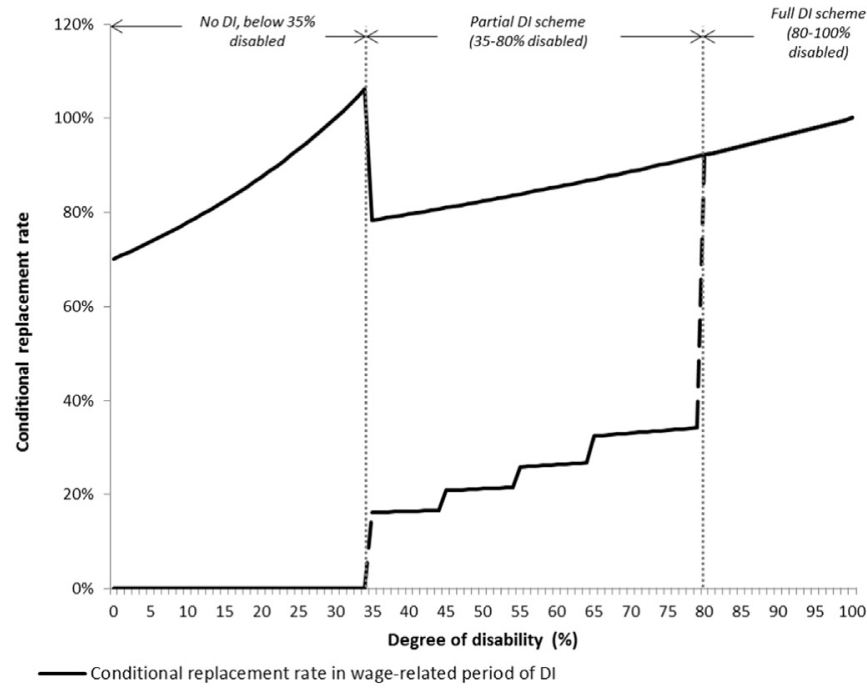

- - Conditional replacement rate in continuation period of DI, no supplementary benefits from social assistance

Fig. 2. Conditional replacement rates for a worker with pre-disability wage earnings of $€ 34,500$, as a function of disability degrees; both for wage-related period and continuation period of DI benefits.

entitlement to supplementary social assistance benefits if the total income drops below the social minimum level in the Netherlands. Finally, we assume that the earning capacity that is measured is equal to its true value. As a result, wage earnings cannot be higher than the earning capacity. As we will argue on, we need to drop this assumption in order to explain exits from partial DI to full work resumption.

In what follows, we first analyze the decision of the worker to use his or her earnings capacity to its full extent, or not. Next, we assume a fixed level of the disability degree, so as to analyze the work decision at the intensive margin. We finally assess whether the incentive change may affect the likelihood of full work resumption and the loss of DI benefits.

\subsubsection{Work incidence}

To shed more light on the work decision at the extensive margin, Fig. 2 depicts the conditional replacement rate of the representative worker in the wage-related period and in the continuation period. The $\mathrm{y}$-axis indicates the conditional replacement rate, expressed in percentage values. The $\mathrm{x}$-axis indicates the degree of disability, also expressed in percentage values.

We first consider the conditional replacement rate in the wagerelated period. Without any loss of earnings capacity - i.e., a disability degree of $0 \%$ - the loss of wage earnings due to unemployment is replaced by UI benefits by $70 \%$. Up to the threshold level of a disability degree of $35 \%$, however, the corresponding losses of wage earnings are not compensated by any DI benefits. As a result, the conditional replacement rate rises to the level of $105 \%$ at the threshold value. For disability degrees between $35 \%$ and $80 \%$, the worker is entitled to DI benefits. Since work resumption no longer implies the loss of DI benefits, it becomes more rewarding to exploit the earning capacity to its full extent; this is reflected by lower conditional replacement rates. Still, the gains from working are not substantial, particularly if the disability degree is close to $80 \%$.

When the wage-related period ends and the continuation phase starts, we observe a decline in the conditional replacement rate for all disability degrees below the threshold of $80 \%$. Below the threshold of $35 \%$, the worker does not receive any income from UI or DI benefits; the conditional replacement rate is thus zero for this range of values of disability degrees. Moreover, partial DI benefits are related to the statutory minimum wage instead of pre-disability earnings if the worker is not employed. For a given disability degree that meets the

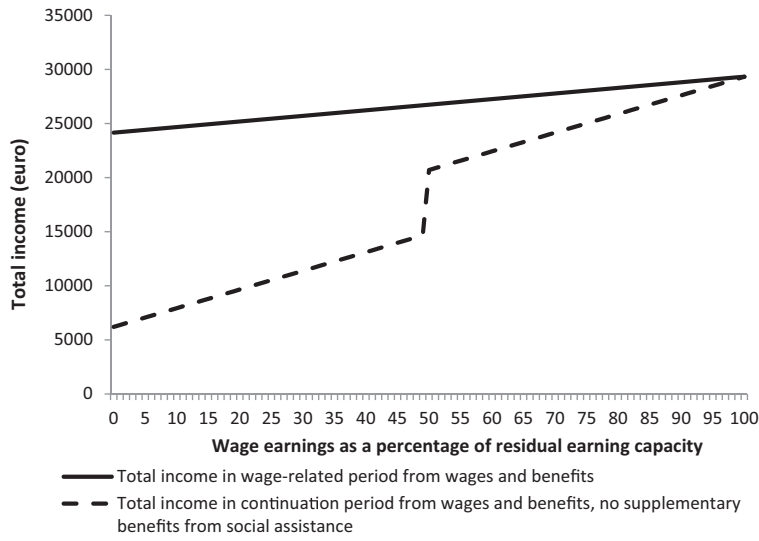

Fig. 3. Total annual income from wage earnings and DI and UI benefits of a worker with pre-disability wage earnings of $€ 34,500$ and a disability degree of $50 \%$; both for wagerelated period and continuation period of DI benefits.

35\%-threshold, this implies a strong decrease in the conditional replacement rate of the representative worker.

\subsubsection{Wage earnings}

Obviously, the worker in the above-mentioned example may consider more options than fully exploiting his or her residual earning capacity or not having any wage earnings at all. Fig. 3 therefore addresses the work decision at the intensive margin for the representative worker - but now with a degree of disability that is fixed at $50 \%$. The worker is thus entitled to partial DI benefits and the residual earning capacity is equal to 17,250 Euros per year. Recall that we assume the earning capacity is measured correctly and exogenous to the worker. As such, the choice the worker faces is on the percentage usage of his or her residual earning capacity.

Fig. 3 shows that the marginal tax rate of increasing work hours is equal to $70 \%$ in the wage-related period of benefit receipt; this reflects the fact that higher earnings are tapered by lower UI benefits. When the continuation period of DI benefits commences, however, the marginal tax rate decreases for all possible values of the percentage usage of the earning capacity. This can be explained by two changes in benefit conditions. First, any increases in wage earnings are no longer tapered by lower UI benefits. This induces a stronger incentive to increase working hours for all usage levels of the earning capacity. Second, there is a discrete jump - or, 'kink' in the level of DI benefits if the worker uses $50 \%$ of his or her earning capacity. We thus expect the worker to increase working hours if he or she is able to, particularly to usage levels the exceed $50 \%$ of the earning capacity.

\subsubsection{Full work resumption}

Suppose that the representative worker initially has a disability degree that exceeds the $35 \%$-threshold, but that his or her 'true' earning capacity increases to a level where the threshold condition is not met anymore. We thus no longer assume that the earning capacity is measured correctly and constant over time. If the worker now decides to increase wage earnings to the new level of the earning capacity, this will ultimately lead to a medical re-assessment and the loss of DI benefits. Thus, the representative worker essentially faces the dilemma to reveal his or her true earning capacity and increase wage earnings while losing DI benefits, or continue receiving DI benefits while having wage earnings equal to the initial earning capacity. In this context, the full loss of DI benefits induces a 'cashcliff' that deters the worker from increasing working hours.

We stated earlier that the income level from DI benefits and wage earnings at the initial level of the earning capacity remains constant when the continuation period commences. Also, the income value from full work resumption will not change either. Accordingly, we 
hypothesize that the exit rate out of DI benefits remains unaffected. ${ }^{6}$ If any, increases in working hours are more likely to occur up to the level of the initial earning capacity - as argued in Section 2.3.2.

\section{Data}

\subsection{Data setup}

Our analysis uses registered individual worker information from UWV. We have monthly observations of all of the disabled workers who entered the partial DI scheme between January 2006 and June 2010. These recipients are followed as long as they remain in the scheme, up to and including December 2013. Our sample consists of almost 700,000 monthly records and 13,063 unique individuals ${ }^{7}-$ for whom we observe several individual characteristics, as well as the length of the wage-related period of DI benefits, degree of disability, residual earning capacity, type of impairment, pre-disability wage and current wage earnings.

Information on individual pre-disability wages and degree of disability can be used as inputs to derive the conditional replacement rates in our sample. In doing so, however, we need to make closing assumptions regarding the receipt of supplementary benefits if income levels drop below the social minimum. In particular, partially disabled workers who do not work in the continuation phase will receive DI benefits that are below the minimum income level in the Netherlands. This level amounts to $70 \%$ of the minimum wage ( $€ 12,400$ in 2013$)$ for single households and $100 \%$ of the minimum wage ( $€$ 17,700 in 2013) for couples, respectively. Without any income from a partner, workers may thus qualify for supplementary social assistance benefits.

Unfortunately, our data do not contain information on partner income or owned assets that determine eligibility to supplementary benefits. This prevents us reconstructing conditional replacement rates for employed workers with sufficient wage earnings. Still, we observe the receipt of income supplements from social assistance for individuals without wage earnings, which enables us to derive two rules of thumb for the construction of conditional replacement rates. To avoid any biases in the construction of our data, we apply these rules to all individuals. The first rule is that none of the individuals that are married receive income supplements. This assumption stems from the observation that only $18 \%$ of married individuals without wage earnings in our sample received income supplements in the continuation phase. The second assumption is that all unmarried individuals receive income supplements from social assistance, up to $70 \%$ of the statutory minimum wage. With $58 \%$ of the individuals that are not married and do not have wage earnings receiving income supplements in the continuation phase, this assumption is more restrictive than the first one. In our analysis, we therefore perform a robustness test with respect to the presence of measurement errors. We return to this issue in Section 5.

\subsection{Data description}

Table 1 presents summary statistics of the variables of partially disabled workers in our sample at different points in time and for different samples. These statistics concern (i) the full sample, measured

\footnotetext{
${ }^{6}$ Using ex ante calculations on the new disability law in 2006, Van Sonsbeek and Gradus (2006) argue that the increased work incentive will not lower the total number of DI benefit recipients, but only increase the likelihood of employment of this group. This is due to the $35 \%$-cash-cliff that deters employed DI recipients from leaving the scheme.

7 Between January 2006 and June 2010, approximately 116,000 people entered the DI scheme, the vast majority of these individuals being fully disabled. Only 19,000 (16\%) of DI awards were deemed partially disabled initially. Moreover, about 3,000 individuals were re-assessed as fully disabled in some months after the initial assessment, due to either deterioration in medical condition or appeals. As the incentive change after the first phase of DI benefits is not relevant for this group, we selected only those workers who remain partially disabled in all observed periods.
}

Table 1

Sample statistics of the inflow of partially disabled benefit recipients (2006-2013).

\begin{tabular}{|c|c|c|c|c|}
\hline & \multicolumn{2}{|c|}{ Average at start DI } & & \\
\hline & \multirow[t]{2}{*}{ All } & \multirow[t]{2}{*}{$\begin{array}{c}\text { DI } \\
\text { exits }\end{array}$} & \multicolumn{2}{|c|}{$\begin{array}{l}\text { Close to incentive } \\
\text { change at } t=T:\end{array}$} \\
\hline & & & $t=T-1$ & $t=T+1$ \\
\hline $\begin{array}{l}\text { Number of individual } \\
\text { observations }\end{array}$ & 13,063 & 3,761 & 11,385 & 11,385 \\
\hline Male (\%) & 54.1 & 56.2 & 53.1 & 53.1 \\
\hline Married (\%) & 54.5 & 56.2 & 53.9 & 53.9 \\
\hline \multicolumn{5}{|l|}{ Age categories (\%) } \\
\hline$<35$ years & 14.5 & 16.0 & 14.8 & 15.0 \\
\hline $35-44$ years & 24.2 & 23.1 & 25.0 & 25.4 \\
\hline $45-54$ years & 33.9 & 22.0 & 35.6 & 35.8 \\
\hline $55-65$ years & 27.4 & 38.9 & 24.6 & 23.8 \\
\hline \multicolumn{5}{|l|}{ Grade of disability (\%) } \\
\hline $35-45 \%$ & 33.3 & 34.8 & 32.3 & 31.9 \\
\hline $46-55 \%$ & 30.4 & 29.1 & 30.5 & 30.6 \\
\hline $56-65 \%$ & 18.7 & 18.9 & 18.9 & 19.1 \\
\hline $66-80 \%$ & 17.7 & 17.3 & 18.2 & 18.3 \\
\hline \multicolumn{5}{|l|}{ Impairment types (\%) } \\
\hline Neoplasms & 7.7 & 11.1 & 7.2 & 7.6 \\
\hline $\begin{array}{l}\text { Mental and behavioral } \\
\text { disorders }\end{array}$ & 34.9 & 32.7 & 35.0 & 35.0 \\
\hline $\begin{array}{l}\text { Diseases of the circulatory } \\
\text { system }\end{array}$ & 16.0 & 16.9 & 15.6 & 15.9 \\
\hline $\begin{array}{l}\text { Diseases of musculoskeletal } \\
\text { system }\end{array}$ & 15.6 & 15.5 & 15.7 & 15.5 \\
\hline Other & 25.8 & 23.8 & 26.5 & 25.9 \\
\hline \multicolumn{5}{|l|}{ Wages and benefits } \\
\hline $\begin{array}{l}\text { Pre-disability wage, euros } \\
\text { per day }\end{array}$ & 125.3 & 117.6 & 131.6 & 131.8 \\
\hline Working status (\%) & 53.5 & 47.2 & 57.7 & 58.7 \\
\hline $\begin{array}{l}\text { Working, more than } 50 \% \text { of } \\
\text { earning capacity (\%) }\end{array}$ & 44.7 & 45.4 & 54.1 & 52.8 \\
\hline Earnings, euros per day & 31.8 & 33.4 & 42.2 & 43.2 \\
\hline $\begin{array}{l}\text { Earnings, euros per day (if } \\
\text { working) }\end{array}$ & 68.6 & 71.1 & 74.2 & 74.7 \\
\hline $\begin{array}{l}\text { Residual earning capacity, } \\
\text { euros per day }\end{array}$ & 60.0 & 60.1 & 60.5 & 60.2 \\
\hline $\begin{array}{l}\text { Conditional replacement } \\
\text { rate }(\%)\end{array}$ & 82.9 & 66.1 & 84.1 & 36.7 \\
\hline $\begin{array}{l}\text { Length wage-related period } \\
\text { (months) }\end{array}$ & 24.3 & 17.6 & 28.0 & 28.0 \\
\hline \multicolumn{5}{|l|}{ Outflow destination (\%) } \\
\hline Recovery & & 50.2 & & \\
\hline Retirement & & 28.4 & & \\
\hline Deceased & & 9.0 & & \\
\hline Other & & 12.3 & & \\
\hline
\end{tabular}

${ }^{a}$ Note the sample statistics that are measured in the last month of DI benefit receipt are based on uncensored DI benefit spells only.

at the first month of DI benefits; (ii) the sample of individuals that exit DI at some point in time, measured at the first month of DI benefit receipt; (iii/iv) the sample of individuals who experienced the incentive change, measured one month before and one month after the wagerelated period ended. Observed variables include gender, age, marital status, pre-disability earnings, disability degree, length of entitlement to the wage-related period, residual earning capacity, type of impairment and current wage earnings. In this respect, it should be noted that the residual earning capacity of workers is measured at the start of the DI benefit period. This value can change only when wage earnings are found to exceed the initial residual earning capacity for a longer period of time.

At the start of the DI benefit spell, $53.5 \%$ of the partially disabled workers in our sample received wage earnings in the time period under investigation. For these workers, the average wage earnings amounted to 68.6 Euros per day, which is $55 \%$ of the average of pre-disability wages. For individuals that leave DI benefits over time (constituting about one-third of our sample), we observe the outflow destination 
(recovery, pension, deceased, or other). About half of these individuals are no longer entitled to DI benefits, as they have recovered; this typically occurs if they start earning wages that exceed $65 \%$ of their pre-disability wage.

From our data, we infer that annual exit rates due to work resumption are around 2\%. Even though we focus on workers with earning capacities, this rate comes close to annual DI exit rates that are observed for comparable OECD countries (2010). ${ }^{8}$ When comparing the second- and third columns in Table 1, we find that individuals leaving the DI scheme tend to be male, older, married and having higher pre-disability wage earnings; this reflects the fact that older workers are more likely to retire and have a higher mortality rate.

Figs. 4 and 5 shed more light on the timing and the size of the work incentive changes that are observed in our data, respectively. In particular, Fig. 4 shows histograms of the entitlement lengths to the wage-related period of DI benefit receipt, both in the period before and after 2008. We argued earlier that these entitlement lengths followed from a step function for intervals in employment history until 2008. Consequently, we observe spikes in the distribution of entitlement lengths at 12, 18, 24, 36, 48 and 60 months until 2008. ${ }^{9}$ Since 2008, however, we observe spikes only at 0 months of DI benefit entitlement (if there is no wage-related benefit entitlement) and 38 months of DI benefit entitlement (if the maximum length of benefit entitlement applies). In addition, Fig. 5 shows the empirical distribution of the changes in the individuals' conditional replacement rates at the moment of the incentive change. The figure shows a large variation in the change in the conditional replacement rates, ranging from zero to decreases of values close to 90 percentage-points. The average drop in conditional replacement rates is 47.4 percentage-points (from $84.1 \%$ to $36.7 \%$ ). The large variation predominantly stems from variation in pre-disability earnings and, to a lesser extent, variation in disability degrees.

Finally, Fig. 6 shows the distribution of the usage percentages of the earning capacity of employed individuals in our data, measured three months before and after incentive change. Both figures do not suggest the presence of 'bunching' effects of usage percentages just above the threshold of $50 \%$. At the same time, we do observe a spike at the point where workers employ $100 \%$ of their earning capacity; this reflects the fact that a substantial group of workers that already worked at the start of DI receipt have their earning capacities set equal to the wage earnings they receive at that moment. We also observe a substantial group of the workers with wage earnings exceeding their registered earnings capacity. This observation largely stems from the fact that small, positive deviations from the initial disability degree do not lead to changes in the assignment to the discrete disability degree classes. Only for a small group of workers the earnings capacity will ultimately be adapted by UWV.

\section{Empirical strategy}

\subsection{Identification strategy}

The key challenge in our analysis is to identify and estimate changes in outcome measures that result from the change in incentives that workers are faced with. Stated differently, we aim to disentangle incentive effects from other (unrelated) changes in the ability to work. We do so by exploiting the variation in the length of the wage-related period of individual workers, allowing us to compare changes in

\footnotetext{
${ }^{8}$ According to OECD (2010), only Australia, the United Kingdom and New Zealand show higher DI exit rates due to work resumption than other countries. Note also that DI exit rates due to full work resumption were substantially higher in the Netherlands until 2006, when the sickness period had not yet been extended from one to two years (Van Sonsbeek and Gradus, 2013).

${ }^{9}$ Note that observed entitlement periods that are not at these spikes stem from the fact that workers may have experienced earlier benefit periods.
}

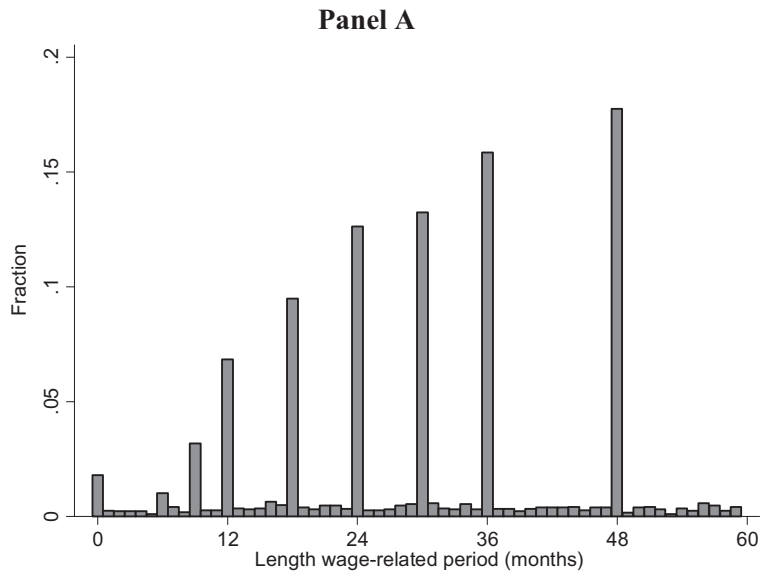

Panel B

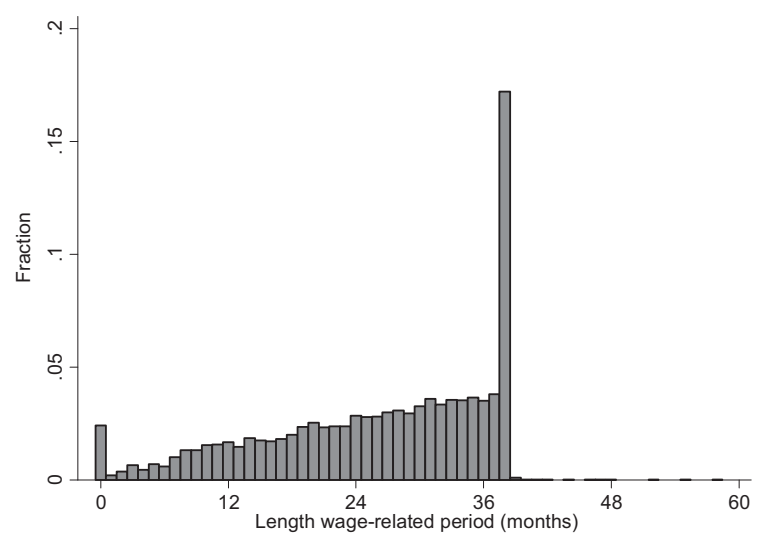

Fig. 4. Distribution of wage-related DI benefit entitlement periods of inflow cohorts of partially disabled workers, until 2008 (Panel A) and since 2008 (Panel B).

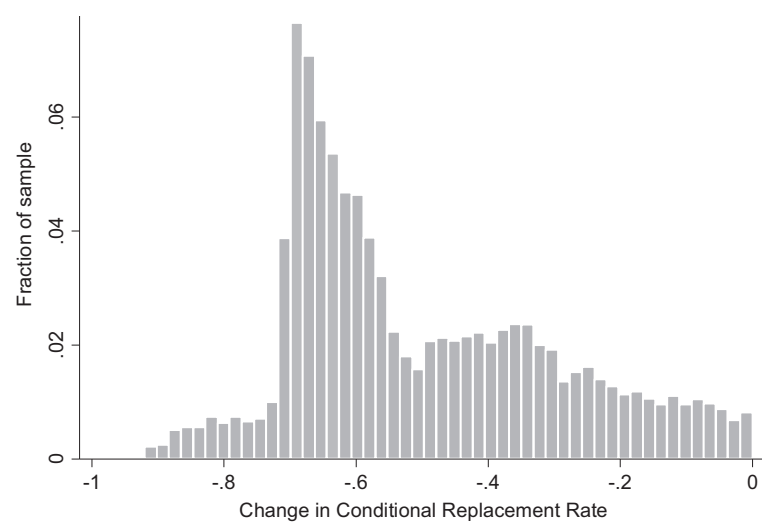

Fig. 5. Empirical distribution of the change in conditional replacement rates, measured at the moment of exhaustion of the wage-related period of DI benefits $(\mathrm{N}=11,385)$.

outcome measures of 'treated' individuals who are close to or after the end of the wage-related period with those of the control group of individuals who are not or not yet affected by the incentive change.

When following this estimation strategy, we need two assumptions to be met. First, individuals should have common baseline patterns of work incidence and wage earnings over the DI benefit spell. If not, behavioral changes around the incentive change may be confounded by differences in baseline patterns. We therefore allow for flexible baseline specifications over the DI benefit spell, both over time and between age categories. In this respect, we argue that age is one of the main drivers of both changes in the ability to work and the entitlement length of the wage-related period. 


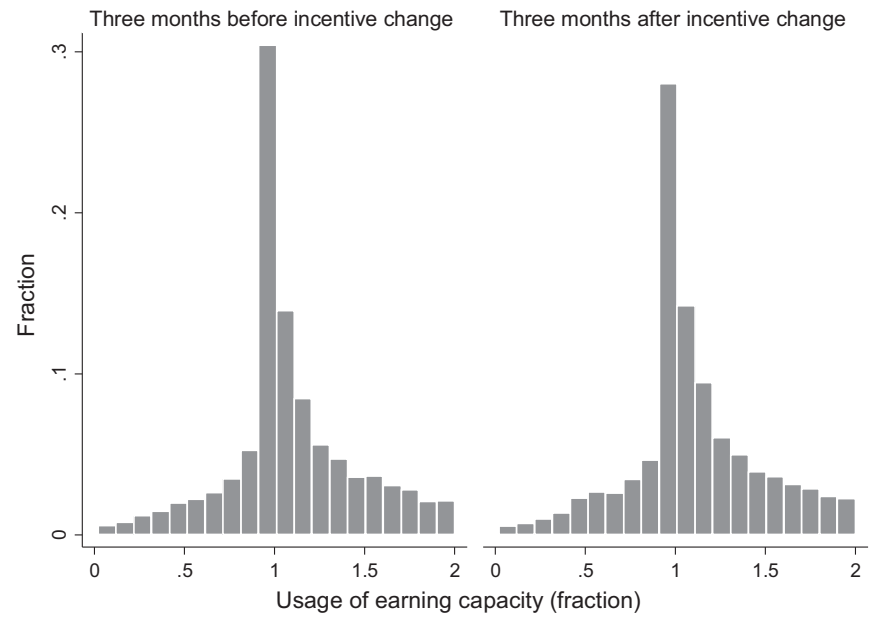

Fig. 6. Empirical distribution of usage fractions of the residual earning capacity of employed workers, measured both three months before and three months after the incentive change.

Our second key assumption is that relevant behavioral changes occur in a specific timeframe around the incentive change. As such, we implicitly assume that workers could respond to the incentive change at reasonably short notice. ${ }^{10}$ If this assumption does not hold, however, zooming into the incentive change may lead to underestimation of the total impact of the incentive change on our outcome measures. As we will show later on, our model specification therefore allows for coefficient estimates that are based on various time windows around the incentive change. This does not only capture anticipation and adaptation effects, but also gives us guidance regarding the proper support that is needed to consider the incentive change.

\subsection{Specification of work incidence and wages}

In our analysis, we specify the work prevalence, $Y$, and wage earnings $W$ of an individual $i(i=1, . N)$ who enters into DI at calendar time $\tau$ both as linear panel regressions. Individuals have age $a_{i}$, with maximum entitlement to the wage-related period that is represented by $T_{i}$, and an elapsed DI benefit duration $t$. This yields the following panel regressions for the full sample of partially disabled individuals:

$$
\begin{aligned}
Y_{i t, \tau}\left(a_{i}, t_{i}, T_{i}\right)= & \alpha_{i}^{Y}+\boldsymbol{\beta}_{\tau}^{Y}+\sum_{k=1}^{K} I_{k}\left(\underline{a}_{k}<a_{i} \leq \bar{a}_{k}\right) \psi_{k}^{Y}\left(t_{i}\right) \\
& +\gamma^{Y, S} I\left(T_{i}-\Delta T<t_{i} \leq T_{i}+\Delta T\right) \\
& +\gamma^{Y, L} I\left(t_{i}>T_{i}+\Delta T\right)+\varepsilon_{i t}^{Y}
\end{aligned}
$$

and, for the sample of partially disabled individuals that are employed,

$$
\begin{aligned}
W_{i t, \tau}\left(a_{i}, t_{i}, T_{i}\right)= & \alpha_{i}^{W}+\boldsymbol{\beta}_{\tau}^{W}+\sum_{k=1}^{K} I_{k}\left(\underline{a}_{k}<a_{i} \leq \bar{a}_{k}\right) \psi_{k}^{W}\left(t_{i}\right) \\
& +\gamma^{W, S} I\left(T_{i}-\Delta T<t_{i} \leq T_{i}+\Delta T\right) \\
& +\gamma^{W, L} I\left(t_{i}>T_{i}+\Delta T\right)+\varepsilon_{i t}^{W} .
\end{aligned}
$$

The successive parts of Eqs. (6) and (7) can be explained as follows. First, individual fixed effects are denoted by $\alpha^{Y}$ and $\alpha^{W}$, respectively. As such, we effectively exclude not only individuals without entitlement to the wage-related period, but also individuals who exit the DI scheme before the incentive change. Still, one way to exploit 'between-variation' would be to estimate the models without individual fixed effects, while including controls for all possible lengths of entitlement to the

\footnotetext{
${ }^{10}$ This is a common assumption in the empirical literature on UI benefit exhaustion effects (see e.g. Card and Levine, 2000).
}

wage-related benefit period. We follow this strategy as a robustness check to our model.

Second, the vectors $\boldsymbol{\beta}^{Y}$ and $\boldsymbol{\beta}^{W}$ denote the effect of calendar time; these are specified as yearly dummies. Both equations allow for duration dependence, which is denoted as a polynomial functions of elapsed durations $\psi_{k}^{Y}$ and $\psi_{k}^{W}$, that vary across age categories that are indexed by $k(k=1, ., K) .{ }^{11}$ In our benchmark model, we allow duration dependency patterns to differ between five-year age intervals, with $\underline{a}$ and $\bar{a}$ as lower and upper bounds, respectively.

Third, long-term incentive effects on work incidence and wage earnings are denoted as $\gamma^{Y, L}$ and $\gamma^{W, L}$, whereas the effects in the months around the incentive change are denoted as $\gamma^{Y, S}$ and $\gamma^{W, S}$, respectively. Our model thus assumes that workers can respond to the incentive in a timeframe around the incentive change. The time window around the incentive change, $2 \Delta T$, is set equal to six months in our benchmark model, but we also present analyses for different values.

Finally, $\varepsilon_{i t}^{W}$ and $\varepsilon_{i t}^{W}$ denote error terms that are assumed to be I.I.D. Eqs. (3) and (4) can be estimated by standard Fixed Effects (FE) estimation, allowing for standard errors that are clustered at the individual level.

\subsection{Specification of full work resumption}

To estimate the impact of the incentive change on the exit rate into full work resumption, we specify a linear probability model that explains the probability of leaving DI benefits within a certain timeframe. ${ }^{12}$ Similar to De Groot and Van der Klaauw (2014), we take advantage of the fact that the length of wage-related benefits was shortened in 2008 for most UI applications. As these changes differed with respect the work history of workers - with changes that were most substantial for those with long employment histories - we can exploit a difference-in-difference design. In doing so, we use controls for all possible values of employment histories of workers that are observed in the data, so as to estimate the isolated impact of the length of entitlement to the wage-related period. More specifically, we specify the probability of leaving DI benefits for full work resumption within $M$ months after the start of the spell for an individual $i$ with age $a$, who starts at calendar time $\tau$ as follows:

$$
\begin{aligned}
\operatorname{Pr}\left(\tilde{t}_{i, \tau}<M \mid d_{i}=0, X_{i}, h_{i}\right)= & \alpha^{R}+\boldsymbol{\beta}_{\tau}^{R}+\sum_{a} \varphi_{k} I\left(a_{i}=a\right) \\
& +\gamma^{R} T_{i}+X_{i} \delta+\varepsilon_{i, \tau}^{R}
\end{aligned}
$$

with $\tilde{t}$ as the elapsed DI benefit duration that is observed for individual $i$. $d$ denotes a censoring dummy which is equal to one only if the DI benefit duration $\tilde{t}>M$ and right-censoring applies (and zero otherwise). For $d=1$, duration observations are not included in the estimation. We also allow for calendar time effects $\left(\boldsymbol{\beta}_{\tau}^{R}\right)$ that apply to the year of inflow in the DI scheme, and dummy values for all possible values of age as a proxy for work history in our sample; the effect of these dummies is denoted by $\varphi$. We also include individual controls that are in matrix $\boldsymbol{X}$. Finally, the error term, $\varepsilon^{R}$, is assumed to be I.I.D.

\subsection{Graphical evidence}

Our estimation strategy entails a comparison of outcome measures in the months before and after the end of the wage-related period of DI benefits. We thus can perform eyeball tests that compare individuals with different elapsed DI benefit durations, but with equal time

\footnotetext{
${ }^{11}$ As we show later on, duration dependence patterns can also be estimated nonparametrically, as a step function of the number of weeks that have passed with DI benefits. Regarding the goodness-of-fit of our model, this yields model outcomes that are virtually equivalent to the semi-parametric method that we employ.

12 The conventional way of modeling durations is by using proportional hazards. This, however, would require strong semi-parametric assumptions, both on the proportionality of coefficients and on the interdependence of observed and unobserved effects.
} 
Panel A

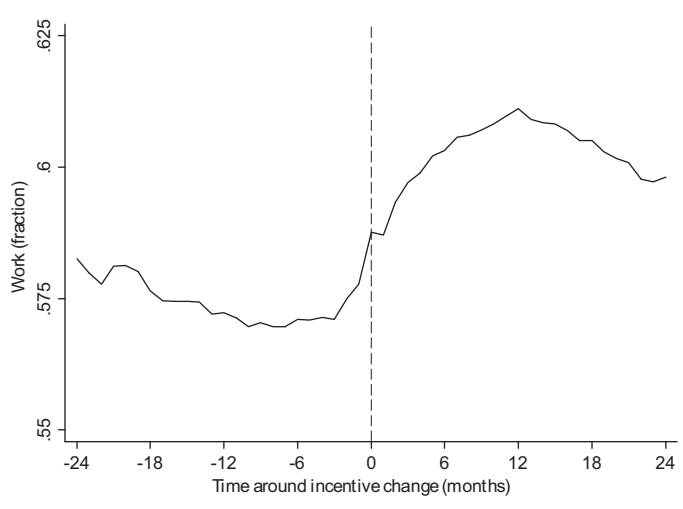

Panel B

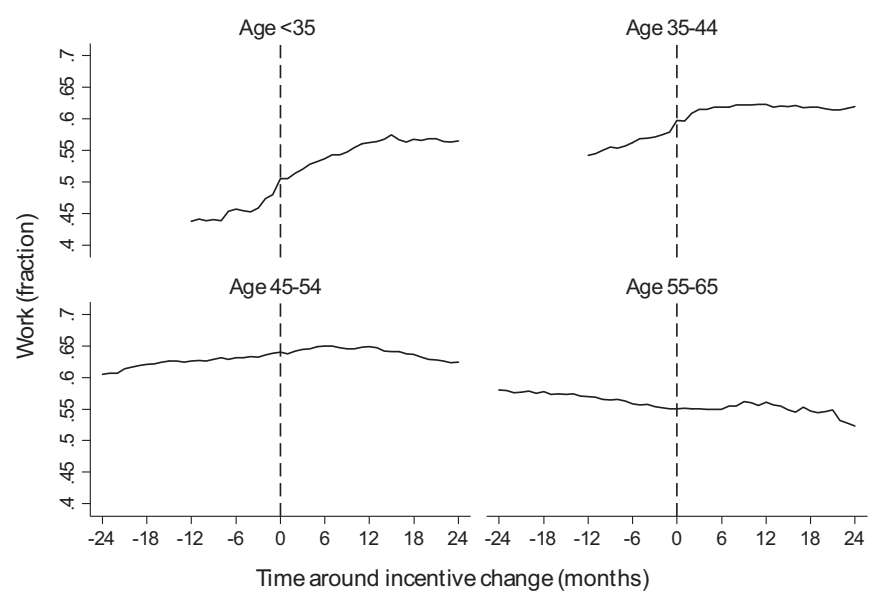

Fig. 7. Average work incidence of partial DI recipients, 24 months before and 24 months after the incentive change due to exhaustion of wage-related benefits. Full sample (Panel A) and sample stratified over age categories (Panel B).

distances - before and after the moment of the incentive change. Following this approach, Figs. 7-10 display the incidence of work, wage earnings of employed workers and the occurrence of DI benefit exits in a frame of 24 months before and 24 months after the moment the wage-related period ends. Note that for the sample of workers that are younger than 45 years of age at the start of their DI spell, this time interval is reduced to 12 months prior to the incentive change. For this group of workers, the maximum entitlement to wage-related benefits is mostly smaller than 24 months.

Panel A of Fig. 7 shows that the fraction of workers that are employed remains more or less stable until the start of the continuation phase of DI benefit receipt, at a level between $57 \%$ and $58 \%$. This suggests no sizeable anticipation effects of the incentive change. Next, we observe an increase in the average work incidence in the year thereafter, up to a level of about $61 \%$. Panel B indicates that this effect is confined to workers below the age of 45 . Moreover, the increase in work incidence is associated with jobs featuring wage earnings that are equal to or exceeding the residual earning capacity - see Fig. 8. Thus, there no evidence for the 'bunching' of jobs with wage earnings below the residual earning capacity but higher than the $50 \%$ condition. This suggests that workers had limited opportunities to find part-time jobs that provide sufficient income to meet the 50\%-condition.

For changes in wage earnings of employed workers around the incentive change, the eyeball test provides less clear-cut outcomes. Panel A of Fig. 9 indicates a modest increase in wage earnings that starts 12 months before the incentive change and ends nine months after it. Again, these effects are most visible for workers below the age of 45 (see Panel B of the figure).

Finally, Fig. 10 portrays the evolution of full work resumption rates
Panel A: 0-49\% usage of residual earning capacity

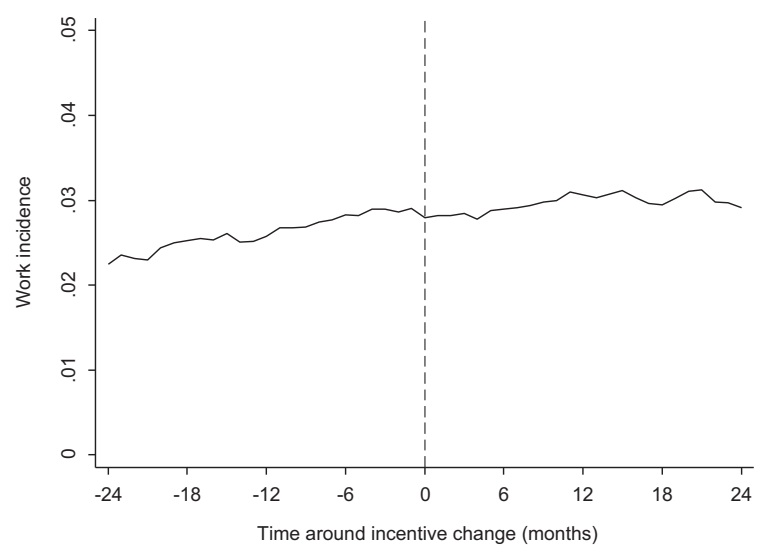

Panel B: 50-99\% usage of residual earning capacity

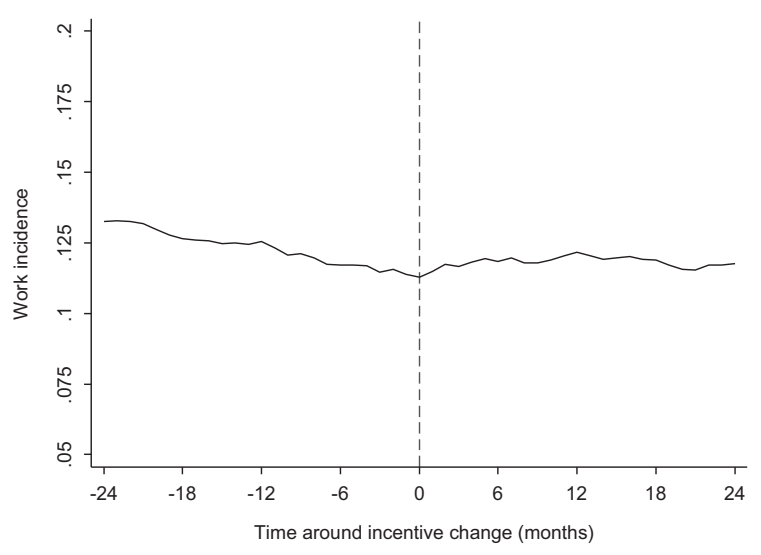

Panel C: $\mathbf{1 0 0 \%}$ usage of residual earning capacity, or more

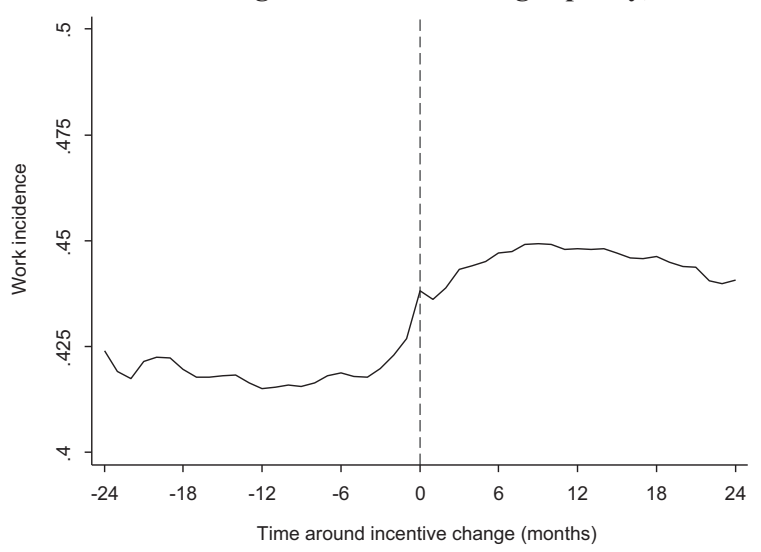

Fig. 8. Average work incidence of partial DI recipients for individuals, stratified with respect to percentage usage of residual earning capacities, 24 months before and 24 months after the incentive change due to exhaustion of wage-related benefits.

and DI exits for other reasons around the time of the incentive change. Remarkably, Panel A shows a strong reduction in full work resumption rates after the incentive change. A possible explanation for this is that the timing of recovery is correlated with the length of the entitlement period to wage-related benefits. This particularly holds for younger workers with shorter entitlement periods and relatively high work resumption rates in the first years of DI benefits. In addition, Panel B shows an increase in DI benefit exits for reasons other than full work resumption in the last months before the increase in incentives. This rise is fully confined to workers reaching the age of 65 and starting 
Panel A

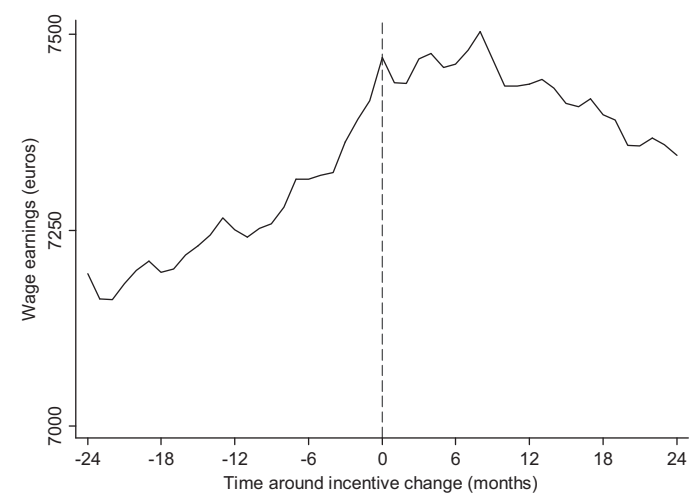

Panel B

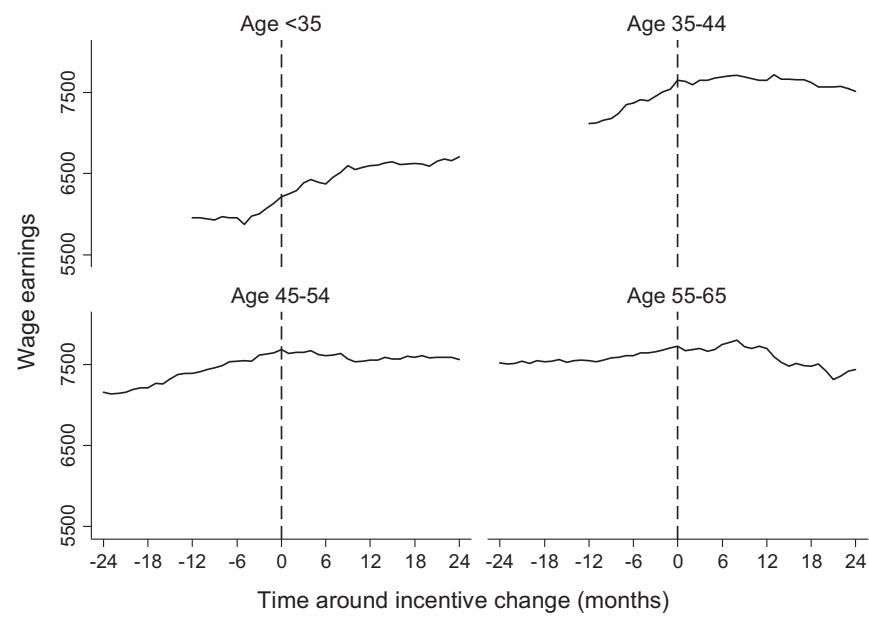

Fig. 9. Average wage earnings of partial DI recipients with employment, 24 months before and 24 months after the incentive change. Wage earnings in eurocents per day. Full sample (Panel A) and stratified over age categories (Panel B).

receipt of pension benefits. For this group, the length of entitlement to the wage-related period is capped by the pension age. ${ }^{13}$

In sum, the eyeball test suggest that younger DI recipients with shorter wage-related entitlement periods are more likely to work and to earn somewhat higher wages when measured just before and after the incentive change. As for the evolution of full work resumption rates, however, the picture seems less clear-cut.

\section{Estimation results}

\subsection{Work incidence}

Table 2 presents the estimates for our fixed-effects (FE) models on the employment probability of partial DI recipients for different model variants. Column (i), which presents results for our 'benchmark model', uses a timeframe around the incentive change of six months and reports five-year age intervals for DI duration dependency profiles. Note that duration dependency profiles are captured by a spline with four polynomials of the time spent in benefits. This setup yields a statistically significant effect estimate of the incentive change of 2.6 percentage-points on work incidence.

We obtain similar results if the incentive effect is estimated with OLS, using dummy values for all possible values of the length of the

\footnotetext{
13 Obviously, if the length of entitlement to the wage-related period would have been set equal to the residual duration until the age of 65 , one would expect a spike in DI exits at the moment of the incentive change. For administrative reasons, however, the formal start of pension benefits is recorded some months earlier than that.
}

Panel A

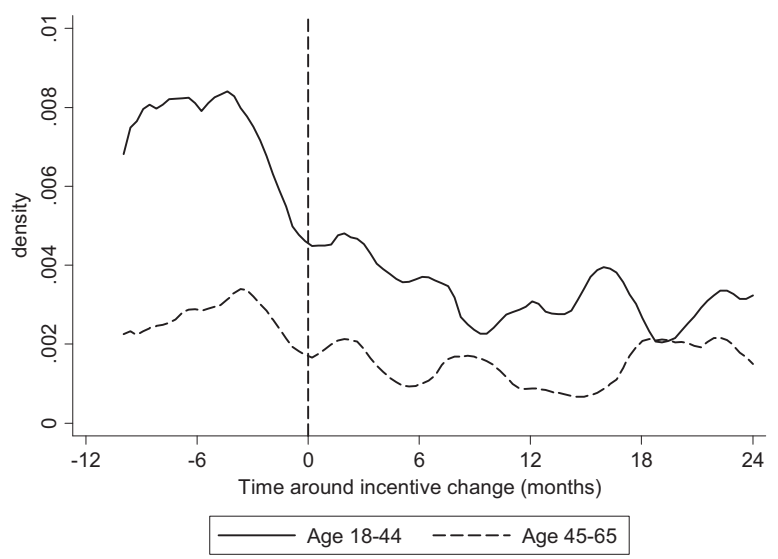

Panel B

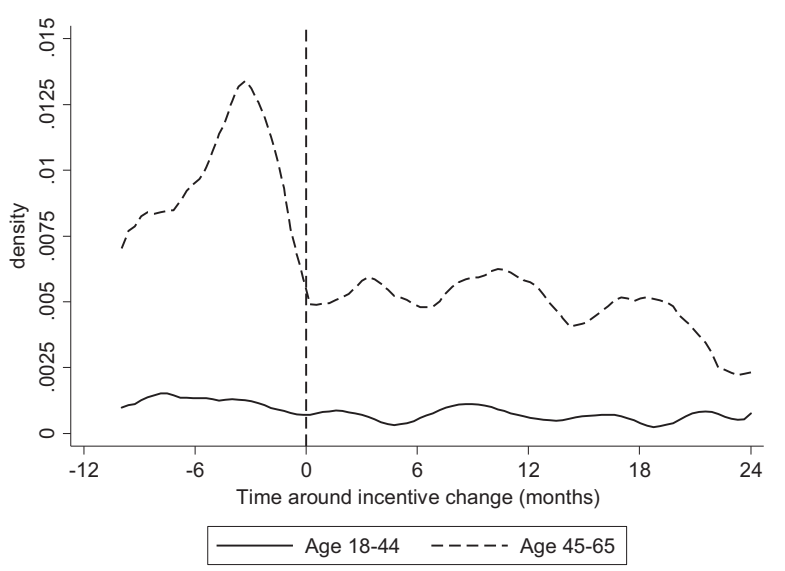

Fig. 10. : Empirical work resumption rates (Panel A) and exit rates for other reasons (Panel B) of partial DI recipients, 24 months before and 24 months after the incentive change, stratified over age categories.

wage-related benefit period as controls - see column (ii). Moreover, the results in columns (iii) and (iv) show that the effect estimates are robust with respect to the length of the time window around the incentive change. This indicates that some workers were able to respond to the incentive at relatively short notice in the months before and after the incentive change. We thus find no evidence pointing to either strong ex ante effects or sizeable lagged effects of the incentive change.

Our estimation results also do not change if we use age intervals for DI duration dependency profiles that are equal to 2.5 years or 10 years - see columns (v) and (vi), respectively. It is only if we assume one single duration dependency profile for all ages that the effect impact is more substantial. This indicates that at least some degree of stratification is needed to obtain consistent estimates of the incentive change effect. We also re-estimated the benchmark model using a fully nonparametric specification of the duration dependency profiles of age groups, using a step function for all possible values of the elapsed DI benefit duration (see the results in column (ix)). Again, this yields coefficient estimates that are virtually equivalent to those obtained for the benchmark model.

\subsection{Wage earnings}

Table 3 reports the estimation results for the incentive change effect on wage earnings for the sample of employed DI benefit recipients. Using the settings of the benchmark model, we find that the incentive increase at the start of the continuation period results in a significant increase of daily wage earnings of 0.97 euro; this corresponds to a 


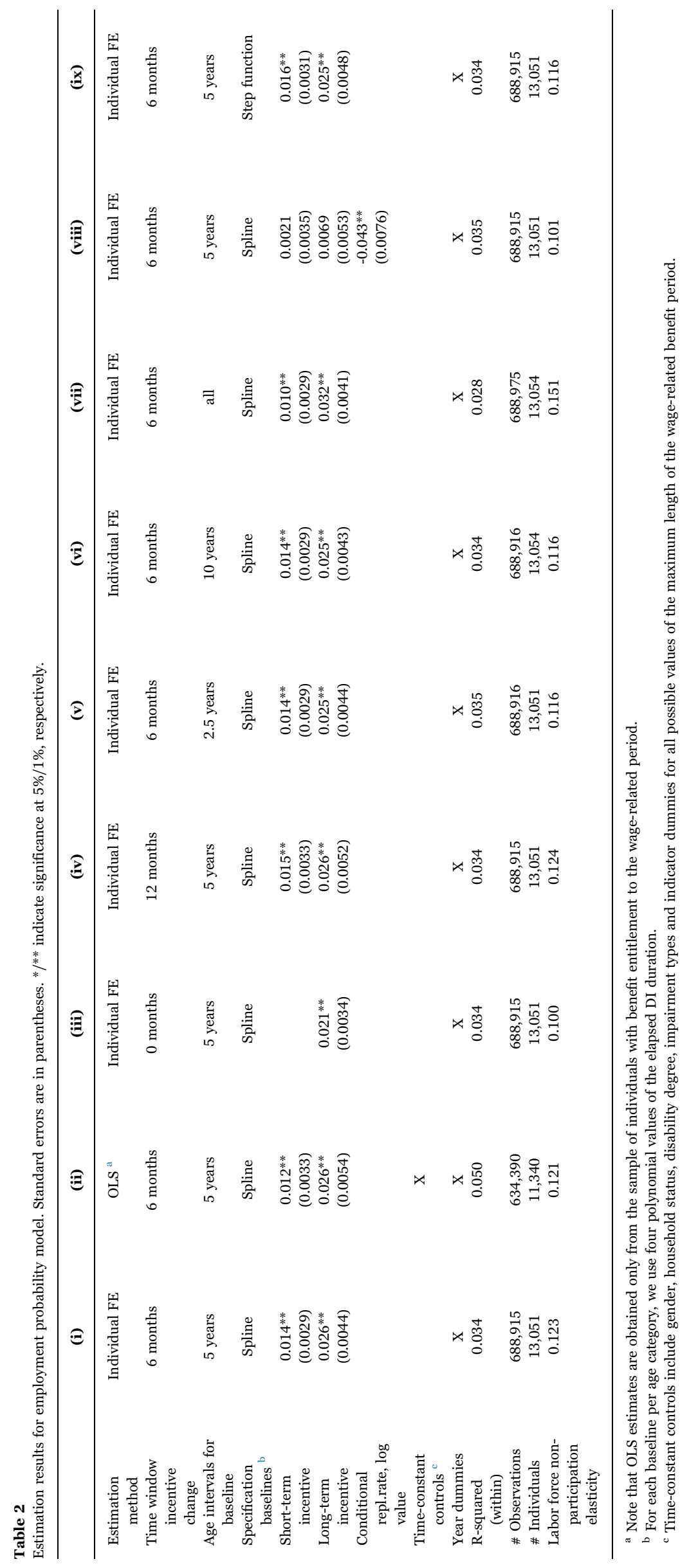


Table 3

Estimation results for wages of employed DI recipients (euros per day). Standard errors are in parentheses. ${ }^{*} / *$ indicate significance at $5 \% / 1 \%$, respectively.

\begin{tabular}{|c|c|c|c|c|c|c|c|c|c|}
\hline & (i) & (ii) & (iii) & (iv) & (v) & (vi) & (vii) & (viii) & (ix) \\
\hline $\begin{array}{r}\text { Estimation } \\
\text { method }\end{array}$ & Individual FE & OLS $^{\text {a }}$ & Individual FE & Individual FE & Individual FE & Individual FE & Individual FE & Individual FE & Individual $\mathrm{FE}$ \\
\hline Sample & Employed & Employed & Employed & Employed & Employed & Employed & Employed & Employed & All \\
\hline $\begin{array}{c}\text { Time window } \\
\text { incentive } \\
\text { change }\end{array}$ & 6 months & 6 months & 0 months & 12 months & 6 months & 6 months & 6 months & 6 months & 6 months \\
\hline $\begin{array}{l}\text { Age intervals } \\
\text { baseline }\end{array}$ & 5 years & 5 years & 5 years & 5 years & 2.5 years & 10 years & all & 5 years & 5 years \\
\hline $\begin{array}{l}\text { Specification } \\
\text { baselines }\end{array}$ & Spline & Spline & Spline & Spline & Spline & Spline & Spline & Step function & Spline \\
\hline Short-term & $0.681^{* *}$ & $1.393^{* *}$ & & $0.663^{* *}$ & $0.673^{* *}$ & $0.686^{* *}$ & $0.531^{*}$ & $0.613^{*}$ & $1.716^{* *}$ \\
\hline incentive & $(0.242)$ & $(0.364)$ & & $(0.284)$ & $(0.242)$ & $(0.246)$ & $(0.228)$ & $(0.277)$ & $(0.259)$ \\
\hline Long-term & $0.971^{* *}$ & 0.828 & $0.775^{* *}$ & $0.994^{*}$ & $0.926^{* *}$ & $1.011^{* *}$ & $1.634^{* *}$ & $1.213^{* *}$ & $2.676^{* * *}$ \\
\hline incentive & $(0.369)$ & $(0.618)$ & $(0.276)$ & $(0.447)$ & $(0.375)$ & $(0.369)$ & $(0.319)$ & $(0.425)$ & $(0.387)$ \\
\hline $\begin{array}{l}\text { Time-constant } \\
\text { controls }^{c}\end{array}$ & & $\mathrm{X}$ & & & & & & & \\
\hline Year dummies & $\mathrm{X}$ & $\mathrm{X}$ & $\mathrm{X}$ & $\mathrm{X}$ & $\mathrm{X}$ & $\mathrm{X}$ & $\mathrm{X}$ & $\mathrm{X}$ & $\mathrm{X}$ \\
\hline R-squared & 0.078 & 0.070 & 0.078 & 0.078 & 0.079 & 0.078 & 0.071 & 0.078 & 0.042 \\
\hline \# Observations & 393,342 & 371,034 & 393,342 & 393,342 & 393,342 & 393,342 & 393,383 & 393,342 & 698,589 \\
\hline \# Individuals & 9,209 & 8,282 & 9,209 & 9,209 & 9,209 & 9,209 & 9,211 & 9,209 & 13,060 \\
\hline
\end{tabular}

${ }^{a}$ Note that OLS estimates are obtained only from the sample of individuals with benefit entitlement to the wage-related period.

${ }^{\mathrm{b}}$ For each baseline per age category, we use four polynomial values of the elapsed DI duration. This yields outcomes that are virtually equivalent to a specification with dummy values for all possible values of elapsed duration.

${ }^{\mathrm{c}}$ Time-constant controls include gender, household status, the degree of disability, impairment types and all possible values of the length of entitlement to the wage-relate d benefit period.

Table 4

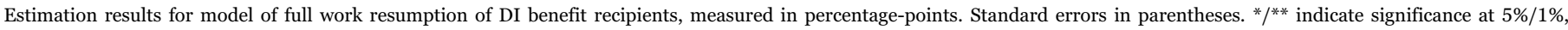
respectively. 12,558 observations.

\begin{tabular}{|c|c|c|c|}
\hline & (i) & (ii) & (iii) \\
\hline \multicolumn{4}{|c|}{ Effect length wage-related benefit period : all individuals (months) } \\
\hline Within 6 months & $-0.014(0.013)$ & $-0.014(0.013)$ & $-0.007(0.014)$ \\
\hline Within 12 months & $-0.027(0.021)$ & $-0.027(0.021)$ & $-0.011(0.022)$ \\
\hline Within 24 months & $-0.003(0.027)$ & $-0.002(0.027)$ & $0.034(0.028)$ \\
\hline \multicolumn{4}{|c|}{ Effect of length wage-related benefit period: employed individuals (months) } \\
\hline Within 6 months & $-0.027(0.032)$ & $-0.025(0.032)$ & $-0.047(0.041)$ \\
\hline Within 12 months & $0.037(0.046)$ & $0.040(0.047)$ & $0.019(0.054)$ \\
\hline Within 24 months & $-0.029(0.071)$ & $-0.027(0.071)$ & $0.005(0.081)$ \\
\hline \multicolumn{4}{|c|}{ Effect of length wage-related benefit period: unemployed individuals (months) } \\
\hline Within 6 months & $-0.021(0.015)$ & $-0.020(0.015)$ & $-0.008(0.016)$ \\
\hline Within 12 months & $-0.047^{*}(0.024)$ & $-0.045(0.024)$ & $-0.016(0.024)$ \\
\hline Within 24 months & $-0.027(0.030)$ & $-0.023(0.030)$ & $0.024(0.031)$ \\
\hline Age dummies & $\mathrm{X}$ & $\mathrm{X}$ & $\mathrm{X}$ \\
\hline Other individual controls ${ }^{\text {a }}$ & & $\mathrm{X}$ & $\mathrm{X}$ \\
\hline Year effects & $\mathrm{X}$ & $\mathrm{X}$ & $\mathrm{X}$ \\
\hline $\begin{array}{l}\text { Year effects x age categories } \\
\text { (5-years) }\end{array}$ & & & $\mathrm{X}$ \\
\hline
\end{tabular}

a The other time-constant controls that are used include gender, household status, all possible degrees of disability and impairment types.

percentage increase of $1.3 \%$ of the average daily wage. To put this result into a broader perspective, column (ix) shows the estimation results when we add unemployed workers - with wage earnings equal to zero - to our sample. This then yields a coefficient estimate of 2.67 euros per day, which corresponds to an increase of $6.3 \%$ of the average wage earnings. Bearing in mind that we estimate a work incidence increase of about $5 \%$ due to the incentive change, the total increase in wage earnings is thus predominantly driven by increases in work at the extensive margin.

Again, our main estimation results are robust with respect to changes in the estimation method, changes in the timeframe around the incentive change, changes in the classification of age groups with distinct duration dependency profiles and changes in the specification of duration dependency. We find effect estimates that are higher only with one common baseline for the elapsed DI benefit duration.

Our analysis shows that the effect of the incentive change on wage hours is limited. This finding is not surprising, as almost all employed workers in our sample earn more than $50 \%$ of their residual earning capacity just before the incentive change. With most of these workers having wage earnings close to or even somewhat higher than the earning capacity that was assessed, increases in wage earnings may result in medical re-assessments and, ultimately, the loss of DI benefits for those with disability degrees close to $35 \%$. This explanation is also relevant for other studies that find that disability recipients tend to 
Table 5

Heterogeneous responses in work incidence. Standard errors in parentheses. $* * *$ indicate significance at $5 \% / 1 \%$, respectively.

\begin{tabular}{|c|c|c|c|}
\hline & \multicolumn{2}{|c|}{ Coefficient estimate } & \multirow{2}{*}{$\begin{array}{l}\begin{array}{l}\text { Labor force } \\
\text { non-participation } \\
\text { elasticity }\end{array} \\
0.123\end{array}$} \\
\hline All & $0.026^{* *}$ & $(0.0044)$ & \\
\hline Male & $0.024^{* *}$ & $(0.0046)$ & 0.144 \\
\hline Female & $0.019^{* *}$ & $(0.0050)$ & 0.198 \\
\hline \multicolumn{4}{|l|}{ Age categories } \\
\hline age $<35$ & $0.050^{* *}$ & $(0.010)$ & 0.513 \\
\hline $35<$ age $\leq 45$ & $0.039^{* *}$ & $(0.0093)$ & 0.294 \\
\hline $45<$ age $\leq 55$ & 0.0058 & $(0.0055)$ & 0.046 \\
\hline $55<$ age $\leq 65$ & 0.0084 & $(0.0056)$ & 0.050 \\
\hline Married & $0.016^{* *}$ & $(0.0045)$ & 0.122 \\
\hline Non-married & $0.027^{* *}$ & $(0.0051)$ & 0.200 \\
\hline \multicolumn{4}{|l|}{ Impairment types } \\
\hline Neoplasms & 0.015 & $(0.012)$ & 0.254 \\
\hline Mental/behavioral disorders & $0.032^{* *}$ & $(0.0063)$ & 0.197 \\
\hline Diseases circulatory system & $0.015^{*}$ & $(0.0074)$ & 0.113 \\
\hline Diseases musculoskeletal & $0.019^{*}$ & $(0.0089)$ & 0.128 \\
\hline Other & $0.015^{*}$ & $(0.0061)$ & 0.140 \\
\hline \multicolumn{4}{|l|}{ Disability degree } \\
\hline $35-45 \%$ & 0.0077 & $(0.0058)$ & 0.066 \\
\hline $46-55 \%$ & $0.017^{* *}$ & $(0.0058)$ & 0.142 \\
\hline $56-65 \%$ & $0.030^{* *}$ & $(0.0079)$ & 0.204 \\
\hline $65-80 \%$ & $0.034^{* *}$ & $(0.0079)$ & 0.178 \\
\hline \multicolumn{4}{|l|}{ Pre-disability wages } \\
\hline$<125$ euros per day & $0.018^{* *}$ & $(0.0048)$ & 0.286 \\
\hline$\geq 125$ euros per day & $0.023^{* *}$ & $(0.0047)$ & 0.116 \\
\hline \multicolumn{4}{|l|}{ Length wage- related period } \\
\hline$<13$ months & $0.039 * *$ & $(0.011)$ & 0.258 \\
\hline 12-24 months & $0.024^{* *}$ & $(0.0062)$ & 0.171 \\
\hline 25-36 months & 0.0081 & $(0.0044)$ & 0.063 \\
\hline$>36$ months & 0.0078 & $(0.0053)$ & 0.055 \\
\hline \multicolumn{4}{|l|}{ Cohorts } \\
\hline $2006-2007$ & $0.026^{* * *}$ & $(0.0054)$ & 0.134 \\
\hline 2008-2012 & $0.026^{* * *}$ & $(0.0079)$ & 0.151 \\
\hline
\end{tabular}

avoid exceeding income thresholds (Campolieti and Riddell, 2012; Weathers and Hemmeter, 2011; Bütler et al., 2015).

\subsection{Full work resumption}

Table 4 presents the estimation results of the linear probability model for full work resumption. Incentive effects are measured after six, 12 and 24 months of benefit receipt for the sample including all DI recipients and separately for those with and without employment at the start of the DI spell. The effect estimates display the percentage-point effect of a one-month increase in the entitlement period to wagerelated benefits. The results in the table allow us to safely conclude that the impact of the length of the entitlement period to wage-related benefits on work resumption is small and insignificant. For instance, the impact of a standard deviation in the entitlement periods - which equals about 12 months - reduces the return-to-work probability for the full sample of DI recipients after 12 months only by $0.027^{*} 12=0.3$ percentage-point. Our findings are robust with respect to the inclusion of various individual controls and a flexible specification of year effects that is interacted with age categories (see columns (ii) and (iii), respectively). ${ }^{14}$ Regarding the sample of unemployed DI recipients who are expected to be affected the most by the incentive change, we also find no significant effects. This renders it likely that DI recipients avoided losing their benefits if they consider that their disability degree

\footnotetext{
${ }^{14}$ In addition, we estimated a Cox proportional hazard model on DI benefit spells to investigate the effect of the incentive change, using a dummy variable for the period after the incentive change. When allowing for baselines to differ between age categories with intervals of five years, we find insignificant effects of the incentive dummy. The results of this model are available upon request.
}

Table 6

Estimated work incidence responses for levels of earning capacity usage (rows = usage at time of start DI spell; columns = usage at time of incentive change). Coefficients are rescaled as a fraction of the full sample. Standard errors in parentheses. ${ }^{*}{ }^{* *}$ indicate significance at $5 \% / 1 \%$, respectively.

\begin{tabular}{|c|c|c|c|c|c|}
\hline \multirow[b]{2}{*}{$\begin{array}{l}\text { Wage } \\
\text { earnings at } \\
\text { start of DI as } \\
\text { \% of earning } \\
\text { capacity }^{\text {a }}\end{array}$} & \multicolumn{5}{|c|}{$\begin{array}{l}\text { Wage earnings at moment of incentive change, as a } \\
\text { percentage of residual earning capacity }\end{array}$} \\
\hline & 0\% & $0-49 \%$ & $50-99 \%$ & $\begin{array}{l}100 \% \text { or } \\
\text { more }\end{array}$ & $\begin{array}{c}\text { Wage } \\
\text { earnings } \\
\text { (euros } \\
\text { p.day) }\end{array}$ \\
\hline $0 \%$ & $\begin{array}{l}-0.026 * * \\
(0.0028)\end{array}$ & $\begin{array}{c}0.0013 \\
(0.0014)\end{array}$ & $\begin{array}{l}0.0073^{* *} \\
(0.0021)\end{array}$ & $\begin{array}{r}0.018^{* *} \\
(0.0022)\end{array}$ & $\begin{array}{c}1.95^{* *} \\
(0.224)\end{array}$ \\
\hline $0-49 \%$ & $\begin{array}{l}-0.0002 \\
(0.0013)\end{array}$ & $\begin{array}{l}-0.0026^{*} \\
(0.0013)\end{array}$ & $\begin{array}{c}0.0008 \\
(0.0012)\end{array}$ & $\begin{array}{c}0.0019 \\
(0.0013)\end{array}$ & $\begin{array}{c}0.183 \\
(0.098)\end{array}$ \\
\hline $50-99 \%$ & $\begin{array}{c}0.0005 \\
(0.0015)\end{array}$ & $\begin{array}{l}-0.0006 \\
(0.0008)\end{array}$ & $\begin{array}{l}-0.011^{* *} \\
(0.0024)\end{array}$ & $\begin{array}{c}0.011^{* *} \\
(0.0023)\end{array}$ & $\begin{array}{c}0.245 \\
(0.145)\end{array}$ \\
\hline $100 \%$ or more & $\begin{array}{l}-0.013^{* *} \\
(0.0020)\end{array}$ & $\begin{array}{c}0.0011 \\
(0.0008)\end{array}$ & $\begin{array}{c}0.0033^{*} \\
(0.0016)\end{array}$ & $\begin{array}{l}0.0082^{* *} \\
(0.0019)\end{array}$ & $\begin{array}{l}1.16^{* *} \\
(0.168)\end{array}$ \\
\hline Full sample ${ }^{\mathrm{b}}$ & $\begin{array}{l}-0.026^{* *} \\
(0.0044)\end{array}$ & $\begin{array}{c}0.0010 \\
(0.0022)\end{array}$ & $\begin{array}{l}-0.0033 \\
(0.0041)\end{array}$ & $\begin{array}{r}0.029^{* *} \\
(0.0045)\end{array}$ & $\begin{array}{l}2.676^{* *} \\
(0.387)\end{array}$ \\
\hline
\end{tabular}

${ }^{\text {a }}$ To avoid endogeneity problems that would occur if wages are measured instantaneously, we take residual earning capacity usage at the start of DI benefits as a reference point.

${ }^{\mathrm{b}}$ Note that the coefficient estimates of the incentive for separate samples $(0 \%, 0-49 \%$, $50-99 \%$ and $100 \%$ or more) do not add up to the coefficient estimate for the full sample. This can be explained by the fact that the shares of the subgroups are different at the time of the incentive change than at the start of DI spells.

drops below $35 \%$ of their pre-disability earnings - as we argued earlier in the previous section.

\subsection{The implied elasticity of labor force non-participation}

In the literature, empirical analyses typically derive the 'labor force non-participation' elasticity to compare labor supply responses with changes in financial incentives. In the current context, the most straightforward way to derive this labor force non-participation elasticity is by relating the coefficient estimate for the incentive change effect on non-participation, which is equal to $-\gamma^{Y, L}$, to the percentage change in the incidence of non-participation of DI benefit recipients $(1-Y)$. The labor force non-participation elasticity $e$ is then calculated as

$e=\frac{-\gamma^{Y, L} /\left(1-\bar{Y}_{T}\right)}{\left(\overline{C R R}_{T+1}-\overline{C R R}_{T}\right) / \overline{C R R}_{T}}$

with $\bar{Y}_{T}$ and $\overline{C R R}_{T}$ as the average work incidence and average conditional replacement rate of workers in the month of the incentive change, respectively.

The implied labor force non-participation rate that follows from Eq. (9) equals 0.12. This value is comparable to Kostol and Mogstad (2014), who examine the full population of DI recipients in Norway. On the one hand, one may argue that our analysis focuses on a specific group of workers that were deemed to have substantial residual earning capacities, thus showing higher elasticity rates. On the other hand, however, one should bear in mind that a priori employment rates of the partially disabled workers were already high at the start of DI receipt. If there was heterogeneity in labor market opportunities among individuals with partial DI benefits, there may have been limited room for additional increases in employment.

With changes in conditional replacement rates that vary across individuals, we can also test the hypothesis that employment effect are proportional to the size of the incentive change that individuals are facing. We do so by extending and re-estimating the model for the work 
incidence model with an incentive effect (described by $\eta^{Y}$ ) that is proportional to the change in the log conditional replacement rate:

$\gamma^{Y, S} I\left(T_{i}-\Delta T<t_{i} \leq T_{i}+\Delta T\right)+\gamma^{Y, L} I\left(t_{i}>T_{i}+\Delta T\right)+\eta^{Y} \ln \left(C R R_{i}\right)$.

If work incidence effects at the moment of benefit exhaustion can be fully explained by the incentive change, one would expect that the remaining (constant) effect is equal to zero $\left(\gamma^{Y}=0\right)$. ${ }^{15}$ Moreover, the coefficient estimate of $\eta^{Y}$ can be used to derive the labor force nonparticipation elasticity $e$ in the following way:

$e=\frac{d \ln \left(Y_{T}\right)}{d \ln \left(C R R_{T}\right)}=-\frac{\eta^{Y}}{1-\bar{Y}_{T}}$.

Column (viii) of Table 2 shows the estimation results of the extended panel regression model that includes the log change of the conditional replacement rate as an explanatory. The dummy variable coefficient that measures the remaining incentive effect becomes insignificant, suggesting that work effects are indeed proportional to the incentive change. In addition, the coefficient estimate of the effect of the log conditional replacement rate implies a labor force nonparticipation elasticity that is equal to 0.10 , which is close to the estimate of our benchmark model.

\subsection{Heterogeneous responses}

To shed more light on heterogeneity in responses to the incentive change, we re-estimated our benchmark model of work incidence for different samples in our data. ${ }^{16}$ As Table 5 shows, implied labor force non-participation elasticities are most substantial for individuals that are female, young, non-married and feature low pre-disability earnings and shorter wage-related benefit periods. Additional analyses that interact the incentive effect with all relevant controls reveal that age is the dominant explanatory variable for the size of the employment incentive effect. ${ }^{17}$ In particular, the inclusion of age as an additional control yields small and insignificant effects of the length of the wagerelated benefit period. ${ }^{18}$ This suggests that age in itself, rather than the length of the wage-related benefit period, determines the responsiveness to incentives.

Table 5 also shows that DI recipients with mental and behavioral disorders respond relatively strongly to the incentive change. This contrasts e.g. with Kostol and Mogstad (2014), who find a lower elasticity rate for the all DI recipients in Norway - using a dataset that also includes fully disabled workers. Strikingly, the effect estimate of the incentive change on employment increases with the disability degree of DI recipients. Again, one explanation for this may be that disabled workers with a disability degree close to the threshold value of $35 \%$ face a higher risk of losing DI benefits altogether if they start working. We also estimated our benchmark model for worker cohorts that entered the partial DI scheme before and after the 2008 reform. This yields effect estimates that are virtually equal in both periods. In light of the reduction in entitlement that affected predominantly older workers with long employment histories, this finding confirms the idea that the incentive response is driven by age, not by the entitlement length to the wagerelated period of DI benefits.

\footnotetext{
15 Related to this argument, the coefficient estimate of $\gamma^{Y}$ also provides a test on the presence of measurement errors in the conditional replacement rate (as discussed in Section 3). If measurement errors cause attenuation bias in $\eta^{Y}$, this is likely to be compensated by higher value estimates of the 'constant' effect of the incentive change, $\gamma^{Y}$.

${ }^{16} \mathrm{We}$ also ran regressions on wage earnings of employed workers for various subsamples. Generally, effect estimates were small and variation across groups was limited.

${ }^{17}$ For expositional reasons, estimation outcomes of the employment model with interacted incentive effects are not included in this paper. They are available upon request.

${ }^{18}$ Similar to the model that explains exit rates out of the DI scheme, the effect of the entitlement period to the wage-related period is then identified from the reform of 2008 .
}

Finally, Table 6 shows the incentive response for samples of individuals with four different levels of usage of their residual earning capacities. Depending on their work status at the start of DI receipt, individuals are categorized into four groups (in rows): not working, wage earnings between $0 \%$ and $49 \%$ of the earning capacity, wage earnings between $50 \%$ and $100 \%$ of the earning capacity and wage earnings equal to or higher than the residual earning capacity. For these groups we estimate the incentive impact on the same four work incidence classes as outcome variables (these are presented in the columns) - but then excluding the first month of benefit receipt as observations. To present size effects that apply for the sample as a whole, we rescale coefficient estimates with the fraction of individuals in the respective groups - also measured at the start of DI receipt. ${ }^{19}$

We infer from Table 6 that those individuals without sufficient wage earnings to meet the $50 \%$ condition at the start of DI receipt do, in fact, respond by earning sufficient wages - which ensures the continued receipt of partial DI benefits that are wage-related. Also, individuals that worked at the start of DI receipt and would have stopped earning wages otherwise, decide not to do so. More strikingly, response effects on work incidence are not significant for employment with earnings higher than $50 \%$ but below $100 \%$ of the residual earnings capacity. Given the strong incentive to earn more than $50 \%$ of the earnings capacity, one may expect a higher impact on this margin. It thus seems that individuals had limited opportunities to find part-time jobs to meet the $50 \%$ criterion only. Finally, we find that the group using between $50 \%$ and $100 \%$ of their residual earning capacity shows a shift toward the group of workers that uses $100 \%$ or somewhat more. As these workers already met the $50 \%$ condition, they probably responded to the loss of (partial) UI benefits.

\section{Summary and policy implications}

This study provides insight into the responsiveness of disabled workers to a dramatic increase in financial work incentives during their DI benefit spell. We focus on workers receiving partial DI benefits in the Netherlands that have substantial residual earning capacities. To investigate whether the incentive change affected the outcome measures of interest, we disentangle incentive effects from other changes in the ability to work that are unrelated to the incentive. We do so by exploiting the variation in the length of the wage-related period of individual workers, which allows us to compare changes in outcome measures of 'treated' individuals (those close to or after the end of the wage-related period) with the control group of individuals (those who are not or have not yet been affected by the incentive change).

According to our estimates, the incentive effect at benefit exhaustion is equal to 2.5 percentage-points for the full sample of partially disabled workers. This effect corresponds to a labor force non-participation elasticity estimate that is equal to 0.12 . The effect is concentrated in a time window of only six months around the incentive change, suggesting that anticipation effects before the incentive change and adaptation effects after the incentive change were limited. Still, the incentive change has only a small impact on the earnings of DI recipients who work and has no significant effect on the exit rate out of DI benefits. From this, we infer that employed workers preferred partial DI benefits to be supplemented by wage earnings, rather than receiving wage earnings from full employment.

There are at least three policy implications that can be drawn from our analysis. To start with, the impact estimate of the change in financial incentives is small when compared to the group of workers

\footnotetext{
${ }^{19}$ As the fractions of these four groups may change over the benefit spell, adding coefficient values per outcome variable may lead to outcomes that deviate from the effect for the full sample.
} 
that is already employed. Even though the incentives were targeted at individuals with residual earning capacities, labor elasticities are comparable to those obtained by Kostol and Mogstad (2014) for disabled workers with much lower a priori employment rates. In contrast, the majority of individuals with wage earnings and partial DI benefits in our sample succeeded in maintaining employment in the sickness period that precedes DI benefit claims. Rather than the financial incentives, it was thus employers who played a key role in maintaining work for partially disabled workers in the sickness period.

Second, our findings confirm results from earlier studies that disabled workers respond positively to earnings disregards and wage subsidies complementing DI benefits, rather than allowing these to induce them to exit the DI scheme (Campolieti and Riddell, 2012; Weathers and Hemmeter, 2011). Partially disabled workers in the Dutch DI scheme had an interest in exploiting their residual earning capacity, but probably avoided the imposition of medical re-assessments that would lower their DI benefits. This calls either for a more frequent and focused use of medical re-assessments in order to prevent cash-cliffs (Moore, 2015) or for incentive schemes that reward full work resumption.

Finally, we find incentive response effects to be confined to younger workers with lower entitlement periods to the wage-related period of DI benefits. When controlling for age effects, however, there is no evidence that longer entitlement periods in itself lead to lower effects. Consequently, the employment effects of shortening entitlement to the more generous wage-related period are probably limited.

\section{Acknowledgements}

The authors would like to thank seminar and conference participants at CPB Netherlands Bureau for Economic Policy Analysis, VU University Amsterdam, Leiden University, the 2016 workshop on Sickness Absence and Social Security in Oslo, the Sixth CAFE workshop in Børkop (Denmark), the 2016 ESPE conference in Berlin and the 2016 EALE conference in Ghent for useful comments to the paper. They also thank Lucien Rondagh (UWV) for preparing the micro dataset and Simone Zwijsen for valuable research assistance. Finally, our paper has benefitted substantially from remarks and suggestions that were made by the editor and two reviewers of Labour Economics.

\section{References}

Autor, D., Duggan, M.G., 2003. The rise in the disability rolls and the decline in unemployment. Q. J. Econ. 118 (1), 157-205.

Autor, D., Duggan, M.G., 2006. The growth in the social security disability rolls: a fiscal crisis unfolding. J. Econ. Perspect. 20 (3), 71-96.

Autor, D., Duggan, M.G., Greenberg, K. and Lyle, D., 2014. The impact of disability benefits on labor supply: Evidence for the VA's Disability Compensation Program, SIEPR Discussion Paper No. 14-010.

Bound, J., 1989. The health and earnings of rejected disability insurance applicants. Am. Econ. Rev. 79 (3), 482-503.

Bütler, M., Deuchert, E., Lechner, M., Staubli, S., Thiemann, P., 2015. Financial Work Incentives for Disability Benefit Recipients: Lessons From a Randomized Field Experiment 2014. IZA J. Labor Policy, 4-18, (Economics Working Paper Series 1406).

Campolieti, M., 2004. Disability insurance benefits and labor supply: some additional evidence. J. Labor Econ. 22 (4), 863-889.

Campolieti, M., Riddell, C., 2012. Disability policy and the labor market: evidence from a natural experiment in Canada 1998-2006. J. Public Econ. 96, 306-316.

Chen, S., van der Klaauw, W., 2008. The work disincentive effects of the disability insurance program in the 1990s. J. Econ. 142 (2), 757-784.

Fevang, E., I. Hardoy and K. Røed, 2013. Getting disabled workers back to work: How important are economic incentives?, IZA Discussion Papers 7137, Institute for the Study of Labor (IZA).

French, E., Song, J., 2014. The effect of disability insurance receipt on labor supply. Am. Econ. J.: Econ. Policy 6 (2), 291-337.

Groot, N.D. and van der Klaauw, B., 2014. The effects of reducing the entitlement period to Unemployment Insurance benefits, IZA Discussion Paper 8336.

Gruber, D., 2000. Disability insurance benefits and labor supply. J. Political Econ. 108 (6), 1162-1183.

Koning, P., van Vuuren, D., 2007. Hidden unemployment in Disability Insurance. Labour $21(4 / 5), 611-636$

Koning, P., Lindeboom, M., 2015. The rise and fall of Disability Insurance enrolment in the Netherlands. J. Econ. Perspect. 29 (2), 151-172.

Kostol, A.R., Mogstad, M., 2014. How financial incentives induce disability insurance recipients to return to work. Am. Econ. Rev. 104 (2), 624, (655).

Maestas, N., Mullen, K.J., Strand, A., 2013. Does disability insurance receipt discourage work? Using examiner assignment to estimate causal effects of SSDI receipt. Am. Econ. Rev. 103 (5), 1797-1829.

Moore, T., 2015. The employment effect of terminating disability benefits. J. Public Econ. 124, 30-43.

OECD, 2010. Sickness, disability and work: breaking the barriers. A synthesis of findings across OECD countries. OECD, Paris.

Tversky, A., Kahneman, D., 1991. Loss aversion in riskless choice: a reference dependent Model. Q. J. Econ. 106, 1039-1061.

UWV, 2013. Basisinformatie CBBS. UWV, Amsterdam/http://www.tracksoftware.nl/wpcontent/uploads/2016/04/Basisinformatie-CBBS.pdf).

UWV, 2016. UWV Monitor arbeidsparticipatie 2015. UWV, Amsterdam.

Van Sonsbeek, J.-M., Gradus, R., 2006. A microsimulation analysis of the 2006 regime change in the Dutch disability scheme. Econ. Model. 23, 427-456.

Van Sonsbeek, J.-M., Gradus, R., 2013. Estimating the effects of recent disability reforms in the Netherlands. Oxf. Econ. Pap. 65 (4), 832-855.

Weathers, R.R., Hemmeter, J., 2011. The impact of changing financial work incentives on the earnings of Social Security Disability Insurance (SSDI) beneficiaries. J. Policy Anal. Manag. 30 (4), 708-728. 